\title{
PAIDEIA E SUSTENTABILIDADE: POR UMA POLÍTICA JURÍDICA QUE DESPERTE A CONSCIÊNCIA ECOLÓGICA
}

\author{
Josemar Soares ${ }^{1}$ \\ Maria Cláudia da Silva Antunes de Souza ${ }^{2}$ \\ Tarcísio Meneghetti ${ }^{3}$
}

\section{RESUMO}

Vive-se em um período de complexo, derivado principalmente de uma crise existencial, resultado de uma educação focada somente em aspectos técnicos que afastou o ser humano do conhecimento dos valores do ser, resultando na dificuldade do processo de autoconhecimento. Isto impacta a relação do ser humano com os outros e com o próprio mundo O objetivo do presente artigo é demonstrar a necessidade de uma educação ecológica (Paideia) capaz de estimular a Política Jurídica se direcionar à Sustentabilidade. O método é o indutivo, por meio de pesquisa bibliográfica.

Palavras-chave: Educação; Sustentabilidade; Paidéia; Política Jurídica; Produção do Direito.

\section{PAIDEA AND SUSTAINABILITY: FOR A LEGAL POLICY THAT AWAKENS ECOLOGICAL AWARENESS}

\begin{abstract}
We live in a complex period, derived mainly from an existential crisis, the result of an education focused only on technical aspects that removed human beings from knowing the values of being, resulting in the difficulty of the self-knowledge process. This impacts the human being's relationship with others and with the world itself. The purpose of this article is to demonstrate the need for an ecological education (Paideia) capable of stimulating the Legal Policy towards Sustainability. The method is inductive, through bibliographic research.
\end{abstract}

Keywords: Education; Sustainability; Paidea; Legal Policy; Production of Law

\section{INTRODUÇÃO}

\footnotetext{
${ }^{1}$ Doutor em Filosofia pela UFRS (2009), Mestre em Ciência Jurídica pela UNIVALIí e Mestre em Educação pela UFSM. Professor no Programa de Pós-Graduação Stricto Sensu em Ciência Jurídica da UNIVALI. https://orcid.org/0000-0001-6412-4094

2 Doutora e Mestre em Derecho Ambiental y Sostenibilidad - UAlicante, Espanha. Mestre em Ciência Jurídica UNIVALI. Professora Permanente no Programa de Pós-Graduação Stricto Sensu em Ciência JurídicaUNIVALI. https://orcid.org/0000-0002-8118-1071

${ }^{3}$ Doutor em Direito pela UNIVALI, em dupla titulação com a Università degli Studi di Perugia, Mestre em Direito pela UFSC. Professor no Programa de Mestrado em Migrações Transnacionais na UNIVALI. https://orcid.org/0000-0002-8118-10710000-0002-5228-6616
} 
O homem e o ambiente em que vive possuem um vínculo indissociável, havendo uma troca de influências entre ambos que para ser positiva e gerar crescimento precisa ser sustentável, harmônica. Vive-se em um período de complexo, derivado principalmente de uma crise existencial, resultado de uma educação focada somente em aspectos técnicos que afastou o ser humano do conhecimento dos valores do ser, resultando na dificuldade do processo de autoconhecimento. Isto impacta a relação do ser humano com os outros e com o próprio mundo. A crise planetária no que se refere ao problema da sustentabilidade é, também, uma crise de formação ética e humanista. A Política Jurídica contemporânea precisa observar o critério da Sustentabilidade, pois esta medeia a interação funcional entre pessoas e instituições em seus impactos ambientais.

Apesar de presente no pensamento grego clássico (Paideia), na atualidade constata-se um período de crise generalizada (LYOTARD, 1998. p. XV-XVI). Fala-se em crise política, econômica (CRUZ; FERRER, 2009, p. 42-60), jurídica, ambiental ${ }^{4}$, científica (HUSSERL, 2002; SANTOS, 1998), entre outras, todas derivadas de uma crise principal: a crise do ser humano (MAY, 2011, p. 14).

Assim, a justificativa da presente pesquisa é argumentar a necessidade de se retomar o conceito grego de paidéia para que a formação atual intensifique os valores do ser e da comunidade como norte, e assim se recupera a percepção da relação "homem e meio ambiente".

Desse modo, o tema central deste estudo, permeia na possibilidade de efetivar uma educação para a Sustentabilidade, auxiliando a política jurídica na sua incumbência de pensar e atualizar o direito para que se torne sempre mais coerente e funcional às necessidades humanas, enquanto indivíduo, sociedade e humanidade na relação com o planeta.

O objetivo do presente artigo é demonstrar a necessidade de uma educação ecológica (Paideia) capaz de estimular a Política Jurídica se direcionar à Sustentabilidade. O problema de pesquisa é: pode uma educação ecológica (Paideia) ser instrumento de estímulo a uma

\footnotetext{
4 "As leis do mercado se aplicam, de forma equitativa, às coisas escolhidas e aos selecionadores. Só as mercadorias podem entrar nos templos de consumo por direito, seja pela entrada dos 'produtos', seja pela dos 'clientes'. Dentro desses templos, tanto os objetos de adoração como seus adoradores são mercadorias. Os membros da sociedade de consumidores são eles próprios produtos de comodificação. Sua degradação desregulamentada, privatizada, para o domínio da comodificação da política de vida é a principal distinção que separa a sociedade de consumidores de outras formas de convívio humano. Como em uma paródia macabra do imperativo categórico de Kant, os membros da sociedade de consumidores são obrigados a seguir os mesmíssimos padrões comportamentais que gostariam de ver obedecidos pelos objetos de seu consumo". (BAUMAN, 2008. p. 82). Também Maffesoli (2006) e Soares e Souza (2018).
} 
Política Jurídica voltada à Sustentabilidade? O método é o indutivo, por meio de pesquisa bibliográfica.

No primeiro momento aborda-se o argumento da educação ecológica, referencial necessário para a política jurídica, assunto do segundo tópico. Por fim, o terceiro tópico apresenta a formação humanista, a Paideia, como instrumento capaz de ampliar a conscientização ambiental e responsabilização individual e institucional perante o ambiente planetário, movimento necessário para o aprimoramento da política jurídica na contemporaneidade.

\section{EDUCAÇÃO ECOLÓGICA}

O homem é parte do planeta Terra. No corpo do homem encontra-se a mesma proporção de água que há na terra, suas veias escorrem como rios. O organismo do ser humano assimila o oxigênio e devolve o carbono às plantas. (VIDOR, 2009, p. 167).

A vida humana é uma vida no mundo, logo, é impossível isolar o homem (sujeito) do mundo (objeto), nem de fato, nem de conhecimento. (KOJÈVE, 2002, p. 48).

Ecologia vem do grego oikos que significa casa, moradia, e logos, que significa estudo, ciência. A Ecologia é o estudo da morada do homem (VIDOR, 2009, p. 169). A Ecologia deve ser antropocêntrica, pois sendo o ambiente a casa do homem e o responsável por sua criação, só pode ser inteiramente compreendido se tiver o homem como centro. $\mathrm{O}$ ambiente deve ser estudado em sua relação com o homem.

A relação homem e ambiente é fundamental para toda pessoa que busca se conhecer e desenvolver sua identidade, pois a influência externa na consciência de cada um é enorme, fazendo com que muitas vezes o indivíduo seja moldado ao ambiente em vez de se desenvolver como pessoa individuada.

Gaston Bachelard foi um filósofo francês que em sua obra A Poética do Espaço (2012) relatou as diversas influências da casa em seu morador. A casa é sempre expressão da existência e dinâmica psíquica de seu morador. Se o corpo é a primeira casa e sempre fala através do homem, a casa em que se vive é a primeira extensão do corpo e também sempre fala através do homem.

Sabe-se que a manutenção do meio ambiente saudável, isento de prejuízos, que confira a segurança necessária àqueles que estão interligados, por qualquer forma, ao referido 
ambiente, é fundamental a realização de um planejamento e adequação aos novos padrões, redirecionando uma politica sustentável e reflexível (SOUZA, 2016).

Sendo assim quando se fala em sustentabilidade não se pode pensar apenas em preservar a natureza, mas consolidar uma harmonia vital entre homem e ambiente.

Ferrer (2012) afirma que falar de qualidade de vida é falar em harmonia interior, eliminando disfunções como o estresse que impedem que as pessoas sejam elas mesmas, é falar em harmonia com o meio natural, amando, cuidando e defendendo o meio ambiente, para ser um com a natureza, e é falar também em harmonia com os semelhantes, estabelecendo uma relação adequada com a sociedade, para ser um com a humanidade.

Para Ferrer (2012) o objetivo deve ser aquele de assegurar as condições que façam possível a vida humana neste planeta. A sustentabilidade precisa ter relação com a dignidade da vida (SOARES e LOCCHI, 2016). Não basta assegurar a subsistência, a condição humana exige condições dignas de vida.

Ferrer (2012) afirma ainda que o fundamento ético e o princípio jurídico que deve regular o Direito e a sociedade atual é a solidariedade. É o sentimento de solidariedade que impulsiona os indivíduos a compartilhas suas aventuras e desventuras, a colocarem-se ao lado dos desfavorecidos, a perceber os problemas e emoções alheias como se fossem seus próprios. (FERRER, 2003).

Também a filosofia grega pré-socrática, o período conhecido como cosmológico da filosofia, entendia todas as coisas como derivadas da natureza. Tales entendia que tudo era derivada da água, Anaxímenes do ar, Empédocles dos quatro elementos, etc. (VIDOR, 2009, p. 171).

Para os filósofos de Mileto, destaca-se ainda, que neles já havia prenúncio de discurso ontológico, ainda que investigassem o cosmos. Por trás do discurso cosmológico havia já a presença ontológica, que buscava identificar, para além das aparências visíveis externas o que há de fundamental na estrutura da realidade. ${ }^{5}$ Para utilizar os termos dos

\footnotetext{
5 "Quando la filosofia comincia a muovere i primi passi nelle colonie greche dell'Asia minore, nella città di Mileto in particolare, non lo fa afrrontando i problemi della conoscenza, della morale o della politica, bensì il problema cosmologico. Ed è proprio su questo terreno che si avverte immediatamente che il procedimento che essi adottano per risolvere il problema non è più quello del mito ma quello del logos: non più racconti ma concetti e principi. Ciò su cui si interrogano i primi filosofi greci è la natura (physis): la causa della molteplicità dei fenomeni che in essa hanno luogo". (MONDIN, 1998, p. 37).
} 
próprios autores, tais filósofos buscavam a arché (princípio) da physis (natureza), isto é, a causa anterior que explicaria toda a realidade. (REALE, 2003).

Tales é o pioneiro da filosofia naturalista, aquele que segundo Aristóteles e a tradição filosófica teria dito que a "a água é o princípio de todas as coisas". Aristóteles acrescenta que provavelmente Tales teria defendido tal proposição após raciocínios baseados em observações sensíveis, como a de a água fertiliza a terra e gera a vida, de que a vivacidade em geral decorre do úmido, e assim por diante. A plasticidade germinativa da água parece se contrapor ao seco imóvel da terra, de tal forma que a água pareceria ser o motor de geração e transformação de todas as coisas. (REALE, 2003).

O que Tales parece dizer é que a água seria o elemento que explicaria o nascimento e modificação dos entes em geral. Ou seja, mais importante do que discutir o conteúdo da asserção em si é se atentar ao fato de Tales ter sido o primeiro pensador a investigar uma causa inteligível na realidade sem recorrer a argumento de origem mítica ou religiosa. Tales se põe como o observador intelectual que, diante do cosmos e suas maravilhas, tenta apreender sua lógica. (KIRK, RAVEN e SCHOFIELD, 1994).

Mondin lembra que Hegel foi o mais enfático nessa linha interpretativa do pensamento de Tales, ao demonstrar que mais importante do que a discussão sobre a causa material em si (a água) é a busca de encontrar a arché (princípio), e este princípio seria único, uma unidade a qual se resumeria a mutiplicidade de entes do cosmos. Reduzir a multiplicidade de coisas existentes a uma unidade lógica racionalmente compreensível é tarefa, em si mesma, da filosofia.

Embora sejam vários os filósofos pré-socráticos e suas escolas, certas linhas de pensamento que mantém uma unidade entre vários pensadores, há alguns conceitos que são presentes nas teorias de todos eles. Tais ideias precisam ser apreendidas porque abrem portas para um entendimento mais profundo da filosofia dos pré-socráticos. Todas elas se conectam a pergunta fundamental dos pré-socráticos: qual é o princípio de todas as coisas? Esta pergunta equivale a investigar o que explica a realidade. Daí se extrai a profunda conexão que estes pensadores tentavam realizar com o mundo que nos rodeia. A filosofia cosmológica grega antiga oferece esta raiz epistemológica que pode facilitar uma melhor interação entre indivíduo e ambiente, na medida em que conscientiza o operador de que precisa compreender 
a lógica que é subjacente ao movimento das coisas no mundo. Na filosofia cosmológica o ser humano é parte do mundo.

Deste entendimento pode-se extrair que o cosmos, a realidade, possui uma estrutura de base que condiciona sua subsistência, de que existem causas e princípios no mundo que explicam seu funcionamento. Isto significa que o homem, ao penetrar neste entendimento, pode passar a viver com maior harmonia e integração junto à lógica da realidade. A sustentabilidade decorre desta condição ontológica do mundo, porque o homem não é um ser isolado da realidade que o circunda, mas produto dos elementos climáticos, geográficos, ecossistêmicos que o envolve. A sustentabilidade é condição ontológica do ambiente porque este se transforma ao longo dos tempos, mas segue gerando as premissas básicas para o nascimento dos vários tipos de vidas. Se o planeta adoecer o próprio homem adoecerá, porque terá arruinado a sua casa.

O direito à sustentabilidade, desse modo, pode ser entendido como aplicação deste entendimento ontológico da sustentabilidade como parte integrante do funcionamento dos ecossistemas.

É a própria lógica da realidade que exige do homem uma tomada de posição, do contrário a qualidade de vida das presentes e futuras gerações estará ameaçada, bem como a preservação da biodiversidade planetária. Neste sentido, se princípios como liberdade e solidariedade, que já foram centrais no pensamento jurídico, e ainda ocupam espaços privilegiados no direito, decorriam de dialéticas inerentes à sociedade humana, a sustentabilidade transcende as relações humanas e atinge a relação com o planeta.

Isto, por outro lado, pode causar algum mal entendido, gerando a insegurança de que apenas ações globais, políticas públicas internacionais ou mediadas pelos Estados poderiam garantir a qualidade do ambiente. A proteção, promoção e reforço do ambiente se inicia com ações humanas individuais, com a autorresponsabilização perante a própria realidade cotidiana, a partir do uso inteligente do consumo de bens, do cuidado com a própria saúde e dos espaços de interação (casa, escola, empresa, locais públicos em geral). Preservando a si mesmo e aos locais e objetos próximos o ser humano pode aprender a preservar o planeta. 


\section{POLÍTICA JURÍDICA ${ }^{6}$}

A Política Jurídica, ou Política do Direito, é a disciplina que estuda o Direito que deve ser e como deva ser em contraponto a dogmática jurídica que estuda a interpretação e aplicação do Direito vigente. (MELO, 2000, p. 77).

Essa disciplina visa alcançar o Direito desejado pela Sociedade, pautando-se, assim, nos critérios de Ética, Justiça, Legitimidade e Utilidade. Para alcançar um Direito que atenda a esses critérios, é necessário a propositura de novas normas, adequação daquelas existentes e a reconceituação do próprio Direito e de seus núcleos. (CAVEDON; VIEIRA, 2011, p. 68-70)

Cabe à Política Jurídica a percepção e apreensão dos desejos e necessidades da Sociedade, introduzindo no sistema jurídico elementos valorativos que foram afastados pela dogmática jurídica em nome da segurança. (CAVEDON; VIEIRA, 2011, p. 65).

Para a Dogmática Jurídica é válida toda norma positivada, desde que autorizada por norma superior, elaborada por autoridade competente e com fiel observância aos ritos do processo legislativo. Porém, para a Política Jurídica, a validade de uma norma não pode ser extraída apenas do seu aspecto formal, mas deve considerar também a legitimidade ética de seu conteúdo e de seus fins. (MELO, 1994, p. 87-88).

Sendo assim, a Política do Direito busca, tanto em fontes formais ou informais, as representações jurídicas do imaginário social que tenha legitimidade na ética, nos princípios de liberdade e igualdade e na estética da convivência humana. (MELO, 1994, p. 131)

A Política do Direito deve buscar um Direito que por meio de suas normas crie um ambiente em que se permite a estética do conviver, que permite aos homens um mínimo de autorrespeito e reconhecimento recíproco da dignidade de cada um, tanto no relacionamento entre si quanto no relacionamento com o ambiente, com o mundo. (MELO, 1994, p. 163)

A Estética aparece como forma de se buscar o mais belo do homem, da norma, do Direito. O Esteticismo é uma expressão usada para significar uma atitude que dê importância superior aos valores estéticos nos fatos da vida. O homem ético é aquele inconformado com o injusto e com o incorreto, o homem estético é não pode conformar-se com o feio produzido pelo injusto e pelo incorreto. Pergunta Osvaldo Ferreira de Melo (1994, p. 62):

Se a grande função da arte é propiciar prazer espiritual, que prazer maior para o ser humano sensível do que o bem-conviver, a comunicação aberta, o

\footnotetext{
${ }^{6}$ Argumentos desta seção, que traz elementos conceituais introdutórios sobre a Política Jurídica, foram objeto de estudo anterior.
} 
sentir-se aceito na diversidade, e descobrir-se com as condições psicológicas e culturais de aceitar o pensar do outro?

A arte de viver é uma constante colocação da estética na convivência, é criar um ambiente favorável para o desenvolvimento da tolerância, do pluralismo de ideias, da aceitação dos valores dos outros. A democracia, na sua acepção para além dos procedimentos formais (MIGLINO, 2006), quando transcende simples arranjos políticos, tem sua estética própria. (MELO, 1994, p. 62)

Buscar o outro como um fim, não como um meio, é relacionar-se de modo estético, de respeitar o outro como ele é, em sua autenticidade, em sua aparência, é situar-se perante o outro para aceitar alegremente sua existência como tal. (LAPOUJADE, 2009).

O que Osvaldo Ferreira de Melo chama de estetização da convivência é fenômeno que só se torna sensível, ou seja, perceptível como atributo de beleza, quando, ao invés da tentativa de justificar-se por meio de ideologias, fundamenta-se na Ética do homem (MELO, 1994, p. 63).

A estética encontra-se presente também na hermenêutica jurídica. Ronald Dworkin, em Uma Questão de Princípio (2000), estabelece um paralelo entre a Hermenêutica Jurídica e a Literária, argumentando que a teoria da Estética pode contribuir muito na interpretação e aplicação de normas. Existem diversos critérios que podem ser adotados para interpretar uma obra, sendo que o crítico precisa escolher aquele que torna a obra a melhor possível. Dessa forma, entre os diversos critérios disponíveis o juiz precisaria escolher aquele que torna a norma a melhor possível, a mais bela, a mais estética.

Se existe uma proporção natural, uma medida que se aplicada dá o melhor ponto de algo, é evidente que em todo ato de decidir (inclusive jurídico) existe uma melhor forma de resolver o caso. É necessário encontrar a proporção para que cada situação, e isto é algo que a formação pela estética pode contribuir com bastante eficácia.

Para a Política Jurídica, é necessário rever as fontes tradicionais do Direito, para privilegiar aquelas que realmente sustentem um Direito novo, desejável, criativo, libertador, racional e que cumpra sua função de responder aos anseios sociais. (MELO, 1994, p. 131).

Os objetivos da ação político-jurídica visam à desconstrução de paradigmas que negam ou impedem a criatividade como um agir permanente, assegurando, assim, a valorização do ser humano e a dignidade de tratamento dos homens entre si e com a natureza. (MELO, 1994, p. 132) 
Na obra Temas Atuais de Política do Direito (1998, p. 13-14), Melo destaca alguns pontos acerca da importância do estudo da Política Jurídica, primeiramente destacando a própria relação entre Política e Direito, afirmando que é possível e desejável uma teorização sobre a conciliação entre Política e Direito, entendidas ambas as categorias em um sentido ético-social e identificados os respectivos conceitos, tanto quanto possível, com a ideia do justo e do legitimamente necessário, ou seja, do socialmente útil.

Em decorrência dessa reciprocidade, o Direito necessita da Política para continuamente renovar-se nas fontes da legitimação, e a Política necessita do Direito para objetivar as reivindicações sociais legítimas, ou seja, propor um sistema de categorias, conceitos, princípios e normas capazes de assegurar não só relações econômicas mais justas, mas também o alcance de um ambiente social realmente ético e estimulador das práticas solidárias. (MELO, 1998, p. 14).

As teorias para fundamentar as técnicas de construção, interpretação e aplicação da norma preocupam-se prioritariamente com a lógica ou outras formalidades, descompromissadas com o conteúdo ético que é próprio da natureza do Direito, sendo usadas indiscriminadamente para desmandos autoritários e atendimento a reivindicações sociais. Já a Política do Direito, arquitetada sobre critérios de prudência e possibilidades e fundamentada em padrões éticos, estará a serviço de um devir desejável e realizável, como proposta criativa aos desafios que forem surgindo. (MELO, 1998, p. 14).

A Política Jurídica não é descritiva, é prescritiva, comprometida com as necessidades e interesses sociais, e sempre interessada nos conhecimentos que lhe podem oferecer a Ciência Jurídica, a Filosofia do Direito e a Sociologia Jurídica, na busca dos aportes teóricos necessários à compreensão dos fenômenos jurídico e social. (MELO, 1998, p. 14)

Importante o destaque de que a Política Jurídica não é pura teoria, mas é voltada para o agir. Toda ação corretiva e criativa recairá sobre o sistema normativo vigente, influindo na sua permanente adequação e aperfeiçoamento. (MELO, 1998, p. 14)

Quem se ocupa da Política Jurídica, ou seja, o Político do Direito, não possui uma formação específica, mas é todo aquele que, impregnado de humanismo jurídico, treinado na crítica social, movido pela utopia de conduzir o Direito para lugares novos, seja capaz de ousar (MELO, 1998, p. 14-15). Devido a esse profundo impacto que a atividade da Política 
Jurídica pode causar no Direito, é fundamental a sua base humanista para garantir resultados compromissados com o desenvolvimento do ser humano. (CANGELOSI e SANTOS, 2019).

Não adianta querer efetivar a sustentabilidade pensando apenas no externo, as pessoas só serão sustentáveis se mudarem dentro, se aprenderem a perceber a si mesmas, e para isso é necessário mudar o atual paradigma da educação, retomando a ideia de paidéia grega, uma formação completa multidisciplinar, e com direcionamento para a Sustentabilidade. Isto serviria de estímulo para o aprimoramento da Política Jurídica e consequentemente para a Produção do Direito.

\section{PARA UMA PAIDEIA VOLTADA À SUSTENTABILIDADE ${ }^{7}$}

A paideia é uma palavra grega que significa cultura, especificamente no sentido de formação do homem, sua melhoria e seu refinamento. É equivalente a palavra latina humanitas: educação do homem como tal, educação devida às "boas artes" peculiares do homem, que o distinguem de todos os outros animais. (ABBAGNANO, 2007).

A paideia grega buscava que todo o cidadão grego tivesse uma formação exemplar, desde a ginástica, buscando um ideal físico, passando pelas artes, até os ofícios técnicos. $\mathrm{O}$ cidadão deveria ser virtuoso e exercer com maestria seu papel na pólis.

$\mathrm{Na}$ Paideia a formação do indivíduo não era desconectada do mundo, seja este no sentido de polis, de comunidade política, ou da natureza. O ser humano, nesta visão, é uma parte do todo, um elemento dentro de percepção cosmológica. Se o humano não é causa de si mesmo, mas parte de um sistema mais vasto, precisa entender como se situar, como viver harmoniosamente neste contexto.

A partir desses pressupostos será possível colher contribuições fundamentais da Paideia grega para uma consciência sustentável contemporânea, bem como delineamentos para uma melhor política jurídica diante destes aspectos.

As primeiras obras em que se encontram os ideias da paideia grega são as epopeias Ilíada (1996) e Odisseia (1996), de Homero.

\footnotetext{
7 Alguns argumentos foram objeto de discussão anterior, mas aqui são retomados e realinhados à ideia de Política Jurídica. Nesta seção busca-se estabelecer a conexão entre os dois argumentos, retomando também a dimensão ecológica. Para aprofundamento geral da Paideia como processo histórico e espiritual da formação do homem grego consultar a obra clássica de Jaeger (2001). Sobre a ideia de educação como paideia na história consultar CAROTENUTO (2012).
} 
Homero lançou a pedra fundamental da cultura grega: a atitude de buscar feitos heroicos, realizações extraordinárias. E de fato, o homem grego depois pareceria que em cada atividade, em cada momento buscaria essas conquistas que tendem a transcender a realidade humana.

Depois de Homero outros autores ajudaram a formalizar o espírito grego. Hesíodo (1996) enalteceu o trabalho como condição não apenas de sobrevivência ao mundo físico, mas de cultivo das virtudes éticas, como a honestidade e a justiça.

Esses autores constroem esse cidadão grego que possui como uma de suas características marcantes ao direcionamento à prática, à ação. E não qualquer ação, mas a ação virtuosa, que permite integrar a felicidade individual ao bem comum da polis.

Quando Hesíodo recomenda aos cidadãos serem honestos e não usurparem as propriedades alheias não era meramente uma questão retórica ou moral de promoção de valores, mas sustentar essa ligação entre o ato individual e o bem-estar coletivo. A ética hesiódica, nesse sentido, sugere a necessidade de uma coexistência harmoniosa entre indivíduos, uma dimensão sustentável.

Um cidadão justo não ameaça nem a sua integridade nem a dos demais. Uma sociedade justa inicia-se pelos cidadãos justos. Esse pensamento se desenvolverá de modo tão intenso que poderá ser encontrado na República (2008) de Platão como sua forma acabada e perfeita. A cidade ideal seria perfeita e justa porque partiria de uma educação cultural (Paideia) virtuosa e justa em seus cidadãos.

Essa preocupação fundamental com a ação virtuosa como constituinte da felicidade individual e coletiva também influenciará a Ética a Nicômaco (1985) de Aristóteles. Ainda que a ideia de solidariedade somente encontrará uma construção teórica mais sólida a partir da virtude cristã da caridade e sobretudo com a concepção iluminista de fraternidade, é possível já vislumbrar algumas origens nessa preocupação grega de compatibilizar a prosperidade da cidade com a felicidade do indivíduo.

Essa questão precisaria ser mais fomentada nas discussões sobre a realidade contemporânea, pois raramente observa-se um esforço em combinar interesses individuais e coletivos. Em geral defende-se um interesse individualista que beira o simples egoísmo ou uma noção superficial de preocupação com o bem comum que se limita a defender os 
interesses da maioria. A saúde social depende de elementos e combinações intrínsecas mais complexas, e que pressupõem um cidadão feliz, mas que intervém no bem-estar dos demais.

O objetivo aqui não é retomar a formação grega da forma que era feita, mas a ideia de formação completa que desenvolve o indivíduo para exercer com excelência suas atividades, ter um contato profundo com seu interior, e viver sua vida de forma estética. Não é por menos que um dos principais ideais gregos é o "Conheça-te a ti mesmo.”.

É com esse tipo de formação voltada ao autoconhecimento que se restabelece o vínculo entre o homem e si mesmo e assim também com o ambiente. Da mesma forma, entendendo-se e estando preparando para ser um cidadão virtuoso, e consequentemente, tendo homens virtuosos no poder, existe uma chance de solução da crise moderna.

Werner Jaeger (2001, p. 3) salientou: "Uma educação consciente pode até mudar a natureza física do Homem e suas qualidades, elevando-lhe a capacidade a um nível superior."

O ensino deve proporcionar ao estudante uma autonomia, uma libertação da simples absorção de conteúdo e tornar-se um fazer no mundo, o educando deve interagir, criar, dialogar, deve construir sua identidade enquanto aprende. (WARAT, 1985, p. 115-116).

As pessoas são seres histórico-sociais que se tornaram capazes de comparar, de valorar, de intervir, de escolher, de decidir, de romper, e por tudo isso se fizerem seres éticos. São enquanto estão sendo. Esta é a condição para ser. (FREIRE, 1996, p. 33).

Para a educação e a formação atual proporcionar desenvolvimento, autoconhecimento e realização deve voltar a ter um enfoque humanistas nas bases da paideia e da humanitas dos tempos antigos. A orientação humanista vê o ser que aprende como primordialmente pessoa. O importante para esse tipo de formação é a auto-realização, o crescimento pessoal. O indivíduo deve ser visto como um todo, não somente intelecto, pois é o indivíduo que é a fonte de todos os atos e é essencialmente livre para fazer suas próprias escolhas em cada situação. (MOREIRA, 1990, p. 6).

A paideia contemporânea deve educar para a responsabilização, para os indivíduos se tornarem autossustentáveis. A paideia é formação, é cultivo diário.

A responsabilidade e o dinamismo de vida implantado nesta dimensão coloca o indivíduo e suas instituições como parte íntegra de uma realidade social, política e ambiental em geral que tem fertilidade de transcendência de civilização ecológica - "humanismo verde". (STAFFEN e SANTOS, 2016). 
A paideia contemporânea deve proporcionar ao indivíduo uma maior consciência do critério estabelecido a partir da relação entre a vontade e a natureza (SOUZA e STOHRER, 2017), que conforme Alécio Vidor (2009, p. 131) permite um conhecimento mais exato do ser humano, de uma compreensão de como é constituída a natureza, através dele pode se chegar a indissociável relação existente entre o homem e todo o ambiente a sua volta. (SOARES, 2019).

O critério ou ponto de referência em base ao que se julga o valor adequado do ambiente é o organismo humano, porque ao homem não compete criar o mundo, mas sim aprimorá-lo e adequá-lo para que ele próprio possa viver. O projeto é o homem e a projeção do saber deve estar em função do ser. (VIDOR, 2009, p. 180).

A partir desse critério se tem autoridade para controlar e ganhar o espaço da própria vida, pois assim exercita-se um princípio que constitui o indivíduo síncrono e coincidente com as leis do real.

O critério é o ponto fundamental para identificar o bem e distingui-lo do mal e é constituído pelo modo de ser humano, pela sua natureza, pelo modo como foi constituído em seu ser e não apenas pelo modo de pensar. O critério sempre confirma a identidade humana e discrimina o que convém para reforçar o humano e apontar o que é útil e benéfico em cada relação, porém, para encontrar essa percepção, é fundamental o conhecimento de si mesmo, e assim, o conhecimento que foi feito e existe dentro de um contexto organizado, é um elemento de uma ordem ou lei universal. Partindo da compreensão do próprio corpo (REALE, 2002) individual, descobre-se a melhor ordem para dar estrutura ao corpo social. (VIDOR, 2009, p. 130-131).

Através do conhecimento de si, encontra-se qual o critério de natureza, indicando a relação do homem e o seu ambiente e como essa relação deve ocorrer, abrindo-se as portas para uma nova ideia de sustentabilidade.

A partir da Paideia grega pode-se recuperar a compreensão de que a relação funcional do indivíduo com os outros e com o ambiente começa na adequada relação consigo mesmo, por meio do cuidado com o corpo, com os locais de convívio, com o respeito à dignidade do outro, da sociedade e dos ecossistemas. A Paideia grega parte de uma dimensão cosmológica, na qual o ser humano não é um elemento separado, mas parte integrante de um sistem mais complexo, que é a própria realidade. 
Transportando a reflexão para os dias atuais não se requer aqui um retorno aos gregos, mas a atualização de uma pedagogia que responsabilize o ser humano enquanto indivíduo, sociedade e instituição. Uma Política Jurídica, tal como visto na seção 2 do presente trabalho, deve atender a critérios éticos, estéticos, que permeiem a coordenação dos indivíduos ao bem comum. Em tempos de globalização isto implica uma capacidade de se movimentar a política jurídica inclusive em dimensões transnacionais. A Política Jurídica lida com aquilo que deveria ser o direito, de como aprimorar as regras e instituições para que se tornem mais funcionais ao ser humano, enquanto pessoa e sociedade. No entanto, para ser eficiente, ela precisa ser pensada não apenas como direito, mas também como dever.

Operadores jurídicos capacitados a pensarem política jurídica que seja instrumento de mediação de melhor interação homem-ambiente dependem de uma profunda autorresponsabilização, de uma percepção ecológica da realidade, em sentido grego do oikos como casa, lar. Portanto, uma Paideia contemporânea, capaz de estimular a responsabilização individual e social, em pessoas, instituições e Estados poderia auxiliar na criação de Políticas Jurídicas eficazes, na medida em que favoreceriam a consciência ecológica e sustentável.

\section{CONSIDERAÇÕES FINAIS}

Conclui-se o presente artigo com a observação que para efetivar a sustentabilidade é preciso despertar a consciência ecológica planetária, mas não há como preservar o ambiente externo quando não se cuida primeiro de si. É urgente, então, uma pedagogia contemporânea direcionada à sustentabilidade, capaz de estimular inclusive a política jurídica na produção de um direito mais sustentável, possível de preservar a qualidade de vida para as gerações atuais e futuras.

Um dos principais motivos da falta de sustentabilidade é a falta de percepção que o homem e o ambiente constituem uma unidade indissociável, fato que deriva da própria falta de autoconhecimento do homem, que ao perder o contato com o próprio ser, não consegue perceber as influências constantes que ocorrem entre indivíduo e ambiente a sua volta.

Para solucionar esse período de crise é necessário constitui uma paideia contemporânea, mudar a educação para que seja um ambiente de participação, de 
desenvolvimento, de realização, que o educando possa aprendendo se conhecer, desenvolver um contato maior com seu próprio ser.

É necessário que a paideia desenvolva no indivíduo um maior contato com o critério que permite medir o real a partir do organismo humano, de sua natureza. A compreensão da realidade e do ambiente só é possível se medida a partir do homem. O critério ético demonstra a relação homem e ambiente e dá as indicações de como a mesma deve ocorrer para ser sustentável. Daqui a possibilidade de políticas jurídicas sustentáveis, inclusive em dimensões transnacionais.

A partir desta consciência ecológica e sustentável capaz de mediar a interação funcional entre indivíduo e ambiente é possível estimular uma política jurídica mais ética e estética na relação com o mundo. Deve-se incentivar uma cultura jurídica responsabilizadora a cada um externalizar historicamente as próprias potencialidades, em benefício de si, dos outros e do planeta. A política jurídica, para pensar soluções viáveis e inteligentes à sociedade, ainda mais em dimensão sustentável global, depende de atores que primeiro possam pensar soluções viáveis para si. Sem uma pedagogia contemporânea voltada à consciência ecológica e sustentável é mais difícil pensar a política jurídica eficiente. A retomada dos estudos da Paideia, mas atualizadas à realidade contemporânea, pode oferecer um caminho de progresso.

\section{REFERÊNCIAS}

ABBAGNANO, Nicola. Dicionário de Filosofia. 5. ed. São Paulo: Martins Fontes, 2007.

ARISTÓTELES. Ética a Nicômacos. 3. ed. Brasília: UnB, 1985.

BACHELARD, Gaston. La poética del espacio.Ciudad de México: Fondo de Cultura Económica, 2012.

BAUMAN, Zygmunt. Vida para o consumo: a transformação das pessoas em mercadorias. Tradução de Carlos Alberto Medeiros. Rio de Janeiro: Jorge Zahar, 2008.

CANGELOSI, Annalisa; SANTOS, Rafael Padilha dos. La formazione umanistica per il Brasile del futuro: Le sfide di efficacia dei diritti e doveri educativi in prospettiva umana, Revista Jurídicas, v. 16, n. 2, p. 45-61, Jul./Dez. 2019. 
CAPRA, Frijot. A Teia da Vida:Uma Nova Compreensão Científica dos Sistemas Vivos. São Paulo: Cultrix, 1996.

CAPRA, Frijot. O Ponto de Mutação: A Ciência, a Sociedade e a Cultura emergente. 28. ed. São Paulo: Cultrix, 2007.

CAROTEnUTO, Margherita. La Paideia Ontica: dai Sumeri a Meneghetti. Roma: Ontopsicologia Editrice, 2012.

CAVEDON, Fernanda de Salles; VIEIRA, Ricardo Stanziola. A Política Jurídica e o Direito Socioambiental:uma contribuição para a decidibilidade dos conflitos jurídicos-ambientais. Novos Estudos Jurídicos, Itajaí, edição especial, p. 60-78, 2011.

CRUZ, Paulo Márcio; FERRER, Gabriel Real. A Crise Financeira Mundial, o Estado e a Democracia Econômica. Revista do Direito, v. 31, p. 42-60, 2009.

DWORKIN, Ronald. Uma Questão de Princípio.São Paulo: Martins Fontes, 2000.

FERRER, Gabriel Real. Calidad de vida, medio ambiente, sostentabilidad y ciudadanía ¿Construimos juntos el Futuro?Novos Estudos Jurídicos, Itajaí, v. 17, n. 3, p. 305-326, set./dez. 2012.

FERRER, Gabriel Real. La solidariedad en el derecho administrativo. Revista de Administración Pública (RAP), n. 161, maio/ago. 2003. p. 123-179.

FERRER, Gabriel Real. Sostenibilidad, transnacionalidad y trasformaciones del Derecho.Revista de Derecho Ambiental, v. 32, p. 65-82, out./dez. 2012.

FREIRE, Paulo. Pedagogia da autonomia: saberes necessários à prática educativa. São Paulo: Paz e Terra, 1996.

GONÇALVES, Marta Regina Gama. Surrealismo Jurídico: a invenção do Cabaret Macunaíma. Uma concepção emancipatória do Direito. 2007. 142 f. Dissertação (Mestrado em Direito) - Faculdade de Direito, Universidade de Brasília, Brasília, 2007.

HESÍODO. Os trabalhos e os dias: primeira parte. São Paulo: Iluminuras, 1996.

HOMERO. A Ilíada. Rio de Janeiro: Ediouro, 1996.

HOMERO. A Odisséia. Rio de Janeiro: Ediouro, 1997. 
HUSSERL, Edmund. La Crisi delle Scienze Europee e la Fenomenologia Transcendentale. Milão: Mondadori, 2002.

JAEGER, Werner. Paidéia: A Formação do Homem Grego. 4. ed. São Paulo: Martins Fontes, 2001 .

KOJÈVÈ, Alexandre. Introdução à leitura de Hegel. Rio de Janeiro: Universidade Estadual do Rio de Janeiro, 2002.

KIRK, J. S; RAVEN, J. E; SCHOFIELD, M. Os filósofos pré-socráticos. Lisboa: Fundação Calouste Gulbenkian, 1994.

LAPOUJADE, María Noel. Notas para una ética de la estética. Revista de Filosofía, Maracaibo, v. 27, n. 61, abr. 2009.

LYOTARD, Jean-François. A Condição Pós-Moderna.Rio de Janeiro: J. Olympio, 1998.

MAFFESOLI, Michel. O tempo das tribos: o declínio do individualismo nas sociedades de massa. 4. ed. Rio de Janeiro: Forense, 2006.

MAY, Rollo. O Homem À Procura de Si Mesmo. 36. ed. Petrópolis: Vozes, 2011.

MELO, Osvaldo Ferreira de. Dicionário de Política Jurídica. Florianópolis: OAB-SC, 2000.

MELO, Osvaldo Ferreira de. Fundamentos da Política Jurídica.Porto Alegre: Sergio Antonio Fabris; CPGD-UFSC, 1994.

MELO, Osvaldo Ferreira de.Temas Atuais de Política do Direito. Porto Alegre: Sergio Antonio Fabris, 1998.

MIGLINO, Arnaldo.Democracia não é apenas procedimento. Curitiba: Juruá, 2006.

MONDIN, Battista. Storia della Metafisica - Vol. 1. Bologna: Studio Domenicano, 1998.

MOREIRA, Marco Antônio. Ensino e Aprendizagem: enfoques teóricos. 3. ed. São Paulo: Moraes, 1990.

PLATÃO. A República. Lisboa: Fundação Calouste Gulbenkian, 2008.

REALE, Govanni. Corpo, alma e saúde: o conceito de Homem de Homero a Platão. São Paulo: Paulus, 2002.

REALE, Giovanni; ANTISERI, Dario. História da Filosofia: Antiguidade e Idade Média. 8. ed. São Paulo: Paulus, 2003.

Rev. de Direito Ambiental e Socioambientalismo | e-ISSN: 2525-9628 | Evento Virtual | v. 6 | n. 1 | p. $80-98$ | Jan/Jun. 2020 
SANTOS, Boaventura de Souza. Um Discurso Sobre as Ciências. 10. ed. Porto: Afrontamento, 1998.

SOARES, Josemar. Sidinei. Critério Ético para as Dimensões da Sustentabilidade e Transnacionalidade. In: Derecho Constitucional - Doctrina. Lima: San Marcos, 2012.

SOARES, Josemar Sidinei. Filosofia do Direito. Curitiba: IESDE, 2019.

SOARES, Josemar Sidinei; LOCCHI, Maria Chiara. O papel do indivíduo na construção da dignidade da pessoa humana, Revista Brasileira de Direito, v. 2, n.1, p. 31-41, jan./jun. 2016.Disponívelem:https://seer.imed.edu.br/index.php/revistadedireito/article/view/1118/835

SOARES, Josemar Sidinei; SOUZA, Maria Cláudia da Silva Antunes de. Sociedade de consumo e o consumismo: implicações existenciais na dimensão da Sustentabilidade, Revista Direito e Desenvolvimento, João Pessoa, v. 9, n. 2, p. 304-318, ago. /dez. 2018. Disponível em:https://periodicos.unipe.br/index.php/direitoedesenvolvimento/article/view/815/568.

Acesso em 10.02.2020.

SOUZA, José Cavalcante de (Org.). Os Pré-Socráticos. São Paulo: Abril Cultural, 1996.

SOUZA, Maria Cláudia da Silva Antunes de. Sustentabilidade Corporativa: uma iniciativa de cunho social transformando o meio ambiente. Revista Jurídica. vol. 04, $\mathrm{n}^{\circ}$. 45, Curitiba, 2016. pp.245-262.

SOUZA, Maria Cláudia da Silva Antunes de; STOHRER, Camila Monteiro Santos. A ecoalfetização no ensino jurídico: novos desafios à consciência ambiental, Revista de Direito Ambiental e Socioambientalismo, v. 3, n. 2, p. 59-74, Jul./Dez. 2017. Disponível em: https://indexlaw.org/index.php/Socioambientalismo/article/view/2436/pdf. Acesso em 10.02.2020.

STAFFEN, Márcio Ricardo; SANTOS, Rafael Padilha dos. O fundamento cultural da dignidade da pessoa humana e sua convergência para o paradigma da Sustentabilidade, Veredas do Direito, Belo Horizonte, v. 13, n. 26, p. 263-288, maio/agosto. 2016. Disponível em: http://revista.domhelder.edu.br/index.php/veredas/article/view/814/507. Acesso em 10.02.2020.

VAZ, Henrique C. de Lima. Escritos de Filosofia IV: Introdução à Ética Filosófica 1. 2. ed. São Paulo: Loyola, 2002.

Rev. de Direito Ambiental e Socioambientalismo | e-ISSN: 2525-9628 | Evento Virtual | v. 6 | n. 1 | p. 80-98 | Jan/Jun. 2020 
VIDOR, Alécio. Filosofia Elementar. Curitiba: IESDE, 2009.

WARAT, Luis Alberto. A Ciência Jurídica e seus Dois Maridos. Santa Cruz do Sul: Faculdades Integradas de Santa Cruz do Sul, 1985. 